\title{
Does Changing Residency Obstetric Call to a Group Model Significantly Impact Patient Continuity?
}

\author{
Lauren Cowen, MD; Elizabeth Loomis, MD; Jocelyn Young, DO, MS
}

BACKGROUND AND OBJECTIVES: Group sharing of prenatal care and inpatient obstetric $(\mathrm{OB})$ call is increasingly replacing single-provider longitudinal models including in family medicine (FM) residencies. Such change in care models could impact continuity of prenatal and delivery care.

The University of Rochester's family medicine residency program changed the resident maternal care coverage to an obstetric group model from a single-provider model in $\mathbf{2 0 1 6}$ to improve work-life balance, which provided an opportunity to examine how these two practice styles impacted provider continuity.

METHODS: We performed a retrospective chart review of family medicine resident-assigned obstetric patients receiving care at the University of Rochester's residency clinic. The study evaluated provider continuity differences in two models of prenatal care and obstetric call: (1) single provider model (SPM) with one primary provider and one backup support resident vs (2) OB group-provider model (GPM) with three to four resident providers and one primary provider.

RESULTS: The average number of different providers seen significantly increased in the GPM vs SPM (3.47 vs $2.87, P=.02)$, however the average percentage of prenatal visits with either a primary or designated backup provider was not statistically different $(83.1 \%$ vs $90.1 \%, P=.07)$. Among delivery continuity measures, there was no significant difference between models in the percentage of deliveries attended by the primary or designated backup residents compared with nongroup providers. ( $76.9 \%$ vs $82.3 \%, P=.51$ ).

CONCLUSIONS: This study provides quantitative evidence on how differing models of residency maternal care coverage impact continuity of care. Study findings did not show an inferiority of an $\mathrm{OB}$ group-provider model compared to a single-provider model when considering how often patients were seen prenatally and delivered by providers from their continuity group.

(Fam Med. 2020;52(3):213-6.)

doi: 10.22454/FamMed.2020.436708

A s work-life balance and provider health become more of an emphasis, ${ }^{1}$ family medicine practices and residency programs are developing methods to promote sharing of patients and oncall duties including obstetric care.
Night float hospital staffing and oncall sharing (eg, rotation of on-call weeknights and/or weekends among the provider team) are two models that help diminish the impact of unexpected work time especially for residents caring for prenatal patients. Additionally, changes in the Accreditation Council for Graduate Medical Education (ACGME) over the past 15 years impacted resident call scheduling, with the restriction of residency physician work duty hours to 80 hours per week and the replacement of numerical minimum deliveries required during family medicine residency with dedicated obstetrics rotation hours. ${ }^{2-4}$

Midwifery has similarly been adapting ${ }^{4}$ and a growing trend is caseload care, a model wherein women receive prenatal, intrapartum, and postpartum care from one to three midwives. ${ }^{5,6}$ This model has support for improving well-being for midwives when compared to shiftbased care models. ${ }^{5,6}$ Recent studies showed that women receiving care through the midwife-led caseload model also were satisfied with their care and had at least comparable outcomes compared to women in other models of care. ${ }^{7-10}$ To date, there have not been studies that investigate differing styles of continuity of prenatal and delivery care in family medicine resident-led models.

The University of Rochester's family medicine residency program recently adjusted the style of resident coverage of maternal care to promote resident well-being. Prior to September 2016, residents assumed full responsibility for individual continuity patients and were

From University of Rochester Family Medicine, Rochester, NY. 
on call continuously for patients after 34 weeks, except during approved time off for which one backup provider was assigned in a single-provider model (SPM). Consistent feedback was received from residents that this system created instances where they were on call continuously for 6 or more months, due to the spacing of their patients' due dates affecting their work-life balance. In response, in September of 2016 the residency program began utilizing obstetric group-provider model (GPM) of care. Each of the three residency classes at the University of Rochester has 12 residents, and in the new GPM model residents were assigned to groups of three or four within their class to share the on-call responsibility of labor and delivery coverage for all patients assigned to the group. Each obstetric patient continued to have a primary resident who oversaw and coordinated as much of the prenatal and labor and delivery care as possible, but was not required to be the first call for triage and delivery. Call is divided in 1-week increments and each group creates its own call schedule.

Given the importance of continuity of care in family medicine, the study objective was to quantifiably compare two care models for prenatal and delivery care in a family medicine residency to identify differences in the frequency patients were treated by providers not in their continuity team, between the SPM and GPM.

\section{Methods}

The University of Rochester Institutional Review Board study approved the study as exempt from review. The study consisted of a retrospective data review on patients who received prenatal care at the University of Rochester family medicine residency clinic and delivered children at Highland Hospital in Rochester, New York. Exclusion criteria included less than 18 years of age, not assigned to residents for maternal care, discontinued receiving medical care at the resident clinic prior to delivery, or delivered their child at an outside hospital. One hundredone patients met inclusion criteria with care provided by 39 family medicine residents (19 in the SPM and 20 in the GPM), and delivery during two time periods representing before and after the change to GPM (JuneDecember 2015 and June-December 2017). For this study, the definition of a primary provider is the one resident assigned as the patient's primary provider in either the SPM or GPM. The designated backup refers to both the assigned backup resident in the SPM and the OB residents in the call group in the GPM. Nongroup provider refers to any providers who cared for these patients during prenatal or delivery care that who not previously met the patient.

We reviewed charts to assess the following: total number of outpatient prenatal visits for the entire pregnancy, number of unique providers seen during routine prenatal visits, and which of the three types of providers was present at delivery. Residents who supervised labor and assisted in vaginal or cesarean delivery were credited as a delivering provider. Data were analyzed using two-tailed $t$ tests with Microsoft Excel software for continuous variable outcomes and using $\chi^{2}$ testing with Prism (GraphPad Software, San Diego, CA) for discrete variables.

\section{Results}

Table 1 shows characteristics from each group of patients with delivery. Prenatal continuity data found that GPM patients had a lower percentage of prenatal visits with their primary provider compared to SPM patients $(46.9 \%$ vs $62.8 \%, P<.001)$. However, there was not a statistically significant difference in the percentage of prenatal visits with either the primary or the designated backup provider in either model (Table 2). As expected due the higher number of providers considered continuity providers in the GPM, the average number of different providers seen during prenatal care did increase in the GPM vs SPM (3.47 vs 2.87, $P=.02$; Table 2).

Among delivery continuity measures, there was a significant difference when comparing how often a provider from the designated backup group, rather than the primary provider attended a delivery, with the GPM having higher rates compared to SPM ( $30.6 \%$ vs $12.8 \%, P=.04$; Table 3$)$. However, there was no significant difference seen between the GPM and SPM models in the number of deliveries attended by either the primary or designated backup provider, rather than a non-group provider $(82.3 \%$ vs $76.9 \%, P=.51$; Table 3).

\section{Discussion}

This study provides quantitative evidence on how differing models of residency maternal care coverage impact continuity of care. As expected, patients did meet more providers prenatally in the GPM, however these were mainly providers who were in their designated care group. A higher number of deliveries were completed by a designated backup provider in the GPM compared to SPM. However, in defining continuity as including all members of the designated backup group, it is significant that the number of deliveries attended by either the primary or the designated backup group provider was not statistically different between the two models. Additionally, there was no difference in how often deliveries were attended by a non-group provider.

Our study was complicated by reassignments during pregnancy, (eg, two patients were reassigned after a resident graduated, multiple GPM teams changed which provider was considered primary). In these cases, our analysis considered the formally reassigned provider to be the primary provider at time of delivery. While prior studies have shown high levels of patient satisfaction with a similar group-call model of care, future research could examine specific aspects of patient experience such as the quantity and quality of 
Table 1: Demographics of Resident Patients per Call Model

\begin{tabular}{|c|c|c|}
\hline & Single Provider Model & Group Provider Model \\
\hline Number of patients & 40 & 61 \\
\hline Number of resident providers & 19 & 20 \\
\hline Age in years, mean (SD) & $26.8(5.8)$ & $27.4(6.1)$ \\
\hline $\begin{array}{l}\text { Race, } \mathrm{n}(\%) \\
\text { Black } \\
\text { White } \\
\text { Hispanic } \\
\text { Asian } \\
\text { American Indian } \\
\text { Other }\end{array}$ & $\begin{array}{l}19(47.5) \\
10(25) \\
1(2.5) \\
4(10) \\
0(0) \\
5(12.5)\end{array}$ & $\begin{array}{c}35(57) \\
13(21) \\
5(8) \\
4(7) \\
1(2) \\
3(5)\end{array}$ \\
\hline $\begin{array}{l}\text { Multiparity after delivery, n (\%) } \\
\text { Primipara } \\
\text { Grand multipara }\end{array}$ & $\begin{array}{c}18(45) \\
2(5)\end{array}$ & $\begin{array}{c}28(46) \\
3(5)\end{array}$ \\
\hline $\begin{array}{l}\text { Delivery type, } \mathrm{n}(\%) \\
\text { Spontaneous vaginal } \\
\text { Assisted vaginal (vacuum or forceps) } \\
\text { Cesarean section }\end{array}$ & $\begin{array}{c}30(75) \\
1(2.5) \\
9(22.5)\end{array}$ & $\begin{array}{l}47(77) \\
5(8) \\
9(15)\end{array}$ \\
\hline $\begin{array}{l}\text { Birth weight } \\
\text { Mean (SD) } \\
\text { Low birth weight, } \mathrm{n}(\%) \\
\text { Macrosomia, n }(\%)\end{array}$ & $\begin{array}{l}3345(521) \\
2(5) \\
3(7.5)\end{array}$ & $\begin{array}{l}3269(472) \\
5(8) \\
3(5)\end{array}$ \\
\hline $\begin{array}{l}\text { Delivery characteristics } \\
\text { Gestational age, mean (SD) } \\
\text { Preterm, n }(\%) \\
\text { Induction, n (\%) } \\
\text { Augmentation for Pitocin, n (\%)* } \\
\text { Epidural, (n (\%) ** }\end{array}$ & $\begin{array}{l}39 \mathrm{w} 4 \mathrm{~d}(1 \mathrm{w} 3 \mathrm{~d}) \\
1(2.5) \\
10(25) \\
5(13) \\
15(37.5)\end{array}$ & $\begin{array}{c}39 \mathrm{w} 4 \mathrm{~d}(1 \mathrm{w} 4 \mathrm{~d}) \\
1(2) \\
22(36) \\
21(34) \\
38(62)\end{array}$ \\
\hline
\end{tabular}

There were no significant differences between the groups except as noted below.

* For noninduced vaginal deliveries only $P=.02$.

** For vaginal deliveries only $P=.03$.

Definitions: SD, standard deviation; Grand multipara, five or more deliveries after 20 weeks gestational age; Low birth weight, fetal weight less than 2,400 g; Macrosomia, fetal weight greater than 4,000 g; Preterm, delivery prior to 37 weeks completed gestation.

Table 2: Prenatal Continuity Measures: Single-Provider Model vs Group-Provider Model

\begin{tabular}{|l|c|c|c|}
\hline & $\begin{array}{c}\text { Single Provider } \\
\text { Model (n=39) }\end{array}$ & $\begin{array}{c}\text { Group Provider } \\
\text { Model (n=62) }\end{array}$ & \multicolumn{1}{|c|}{$\boldsymbol{P}$ Value } \\
\hline Total prenatal visits, average number (SD) & $9.49(2.83)$ & $4.85(3.14)$ & .31 \\
\hline Prenatal visits with primary OB, average \% (SD) & $62.8 \%(.18)$ & $46.9 \%(.24)$ & $<.001$ \\
\hline $\begin{array}{l}\text { Prenatal visits with primary or assigned backup/group, } \\
\text { average \% (SD) }\end{array}$ & $90.1 \%(.12)$ & $83.1 \%(.22)$ \\
\hline $\begin{array}{l}\text { Providers who were not one of the assigned backup/group, } \\
\text { average number (SD) }\end{array}$ & $0.8(1.0)$ & $1.0(1.1)$ & .07 \\
\hline Different providers seen, average number (SD) & $2.9(1.1)$ & $3.5(1.3)$ & $.02 *$ \\
\hline
\end{tabular}

* Statistically significant as defined by $P<.05$, two-tailed $P$ value calculated using unpaired $t$ test.

Definitions: Primary, the resident provider designated to oversee the entire pregnancy in either model; Backup, the single resident provider designated to provide care in the single-provider model when the primary resident is unavailable; Group, the two to three residents designated to share call with the primary resident in the group provider model. 
Table 3: Delivery Continuity Measures: Single-Provider Model vs Group Provider Model

\begin{tabular}{|c|c|c|c|}
\hline & $\begin{array}{l}\text { Single-Provider } \\
\text { Model }(n=39)\end{array}$ & $\begin{array}{l}\text { Group-Provider } \\
\text { Model }(n=62)\end{array}$ & $P$ Value \\
\hline Deliveries attended by primary $\mathrm{OB}, \mathrm{n}(\%)$ & $25(64.1 \%)$ & $32(51.6 \%)$ & .22 \\
\hline Deliveries attended by assigned backup/group, n (\%) & $5(12.8 \%)$ & $19(30.6 \%)$ & $.04^{*}$ \\
\hline Deliveries attended by primary or assigned backup/group, n (\%) & $30(76.9 \%)$ & $51(82.3 \%)$ & .51 \\
\hline $\begin{array}{l}\text { Deliveries in which the delivery provider had seen the patient for } \\
\text { prenatal care, } \mathrm{n}(\%)\end{array}$ & $30(76.9 \%)$ & $49(79.0 \%)$ & .80 \\
\hline
\end{tabular}

* Statistically significant as defined by $P<.05$, two-tailed $P$ score calculated by using $\chi^{2}$ test.

Definitions: Primary, the resident provider designated to oversee the entire pregnancy in either model; Backup, the single resident provider designated to provide care in the single-provider model when the primary resident is unavailable; Group, the two to three residents designated to share call with the primary resident in the group-provider model.

communication with different providers, and whether they chose to have a family medicine maternity provider (rather than an obstetrician) for the purpose of medical care continuity. ${ }^{11}$

As provider satisfaction in caseload midwifery is improved when compared to shift work, a next step could be to survey family medicine residents in differing call models to evaluate their well-being between models of care. ${ }^{7,8}$ Our study is also limited in that it did not include a formal survey of the affected residents assessing which model they preferred. In a similar way, this study did not investigate the patients' perspectives on the change to GPM, though efforts were made to preserve components of continuity, which is an area for further investigation. Additionally, previous studies have found differences in birth outcomes during pregnancy and childbirth when women are cared for in continuity models vs shift-based coverage that supports continuity of care, and these outcomes could be investigated further in the SPM and GPM models..$^{10,12,13}$

This comparison of two models of obstetric care provision in a family medicine residency showed that group care was noninferior to single-provider care when considering how often patients were seen prenatally and delivered by providers from their continuity group. Group care did result in fewer visits and deliveries performed by a patient's primary maternity provider. This indicates that in residency programs, the use of group models of maternity care is a feasible way to preserve aspects of continuity while enacting a program that may enhance resident well-being.

ACKNOWLEDGMENTS: This study was presented at the Family Medicine Education Consortium 2018 Annual Meeting, Nov 9-11, 2018, Rye Brook, NY.

CORRESPONDING AUTHOR: Address correspondence to Dr Lauren Cowen, University of Rochester School of Medicine and Dentistry, 601 Elmwood Ave, Box 233, Rochester, NY 14642. 585-330-0525. lauren_cowen@urmc.rochester.edu.

\section{References}

1. Le Floch B, Bastiaens H, Le Reste JY, et al. Which positive factors determine the GP satisfaction in clinical practice? A systematic literature review. BMC Fam Pract. 2016;17(1):133.

2. Accreditation Council for Graduate Medical Education. ACGME Program Requirements for Graduate Medical Education in Family Medicine. Effective July 1, 2017. https://www. acgme.org/Portals/0/PFAssets/ProgramRequirements/120_family_medicine_2017-07-01.pdf. Accessed December 6, 2017.

3. Sun NZ, Gan R, Snell L, Dolmans D. Use of a night float system to comply with resident duty hours restrictions: perceptions of workplace changes and their effects on professionalism. Acad Med. 2016;91(3):401-408.

4. Wood J. Changing Training Standards for Maternity Care. 2012. In: AAFP Leader Voices Blog [Internet]. http://www.aafp.org/news/blogs/ leadervoices/entry/changing_training_standards_for_maternity.html. Accessed December 6, 2017.

5. Fenwick J, Sidebotham M, Gamble J, Creedy DK. The emotional and professional wellbeing of Australian midwives: A comparison between those providing continuity of midwifery care and those not providing continuity. Women Birth. 2018;31(1):38-43.
6. Jepsen I, Juul S, Foureur M, Sørensen EE, Nøhr EA. Is caseload midwifery a healthy work-form? - A survey of burnout among midwives in Denmark. Sex Reprod Healthc. 2017;11:102-106.

7. Sandall J, Soltani H, Gates S, Shennan A Devane D. Midwife-led continuity models versus other models of care for childbearing women. Cochrane Database Syst Rev. 2016;4:CD004667.

8. Tracy SK, Hartz DL, Tracy MB, et al. Caseload midwifery care versus standard maternity care for women of any risk: M@NGO, a randomised controlled trial. Lancet. 2013;382(9906):17231732 .

9. Homer CS, Leap N, Edwards N, Sandall J. Midwifery continuity of carer in an area of high socio-economic disadvantage in London: A retrospective analysis of Albany Midwifery Practice outcomes using routine data (19972009). Midwifery. 2017;48:1-10.

10. Hodnett ED. Continuity of caregivers for care during pregnancy and childbirth. Cochrane Database Syst Rev. 2000;2(2):CD000062.

11. Shapiro JL. Satisfaction with obstetric care. Patient survey in a family practice shared-call group. Can Fam Physician. 1999;45:651-657.

12. Abenhaim HA, Benjamin A, Koby RD, Kinch RA, Kramer MS. Comparison of obstetric outcomes between on-call and patients' own obstetricians. CMAJ. 2007;177(4):352-356

13. Shear CL, Gipe BT, Mattheis JK, Levy MR. Provider continuity and quality of medical care. A retrospective analysis of prenatal and perinatal outcome. Med Care. 1983;21(12):12041210. 